Mini review

\title{
Recent Progress in Electrochemical Biosensors for Detection of Prostate-Specific Antigen
}

\author{
Yong Chang, Mengmeng Wang, Luyan Wang and Ning Xia ${ }^{*}$
}

Henan Province of Key Laboratory of New Optoelectronic Functional Materials, College of Chemistry and Chemical Engineering, Anyang Normal University, Anyang, Henan 455000, People's Republic of China

*E-mail: xianing82414@csu.edu.cn

doi: $10.20964 / 2018.05 .24$

Received: 1 January 2018 / Accepted: 29 January 2018 / Published: 10 April 2018

Prostate-specific antigen (PSA) is a biomarker for preoperative diagnosis and screening of prostate cancer and monitoring of its post-treatment. Because of their sensitivity, simple in operation, rapid response, and compatibility with miniaturization, electrochemical biosensors have attracted considerable attention for PSA detection. In this work, we focused on the recent progress in the electrochemical methods for PSA detection, including immunosensors, aptasensors and peptide-based biosensors.

Keywords: Prostate cancer; electrochemical biosensors; prostate-specific antigen

\section{$\underline{\text { FULL TEXT }}$}

(C) 2018 The Authors. Published by ESG (www.electrochemsci.org). This article is an open access article distributed under the terms and conditions of the Creative Commons Attribution license (http://creativecommons.org/licenses/by/4.0/). 